\title{
A IMPORTÂNCIA DA PSICOLOGIA PARA REPRODUÇÃO SIMULADA
}

\author{
Paula Roberta Cantagessi ${ }^{1}$
}

RESUMO: A Reprodução Simulada está prevista art. $7^{0}$ do Código de Processo Penal e consiste em atividades periciais para verificar a possibilidade da existência de infrações penais de determinada forma; as autoridades policiais podem (exigir) a reprodução simulada de fatos, desde que isso não viole a moral ou a ordem pública, visando determinar a mecânica e o modus operandi do criminoso, além de esclarecer aspectos relevantes do crime, e identificar agravantes, como por exemplo a premeditação. A pesquisa apresenta a importância da psicologia para Reprodução Simulada, por meio de uma revisão bibliográfica e análise de dados survey com 54 respondentes. Os dados da pesquisa demonstararm que apenas $7.5 \%$ dos respondentes já trabalharam em casos de RS. Estes dados refletem a falta de resolução de homicícios no país. A falta de recursos das forças policiais e de investigação, bem como a precariedade dos inqueritos, entre outros fatores, contribuem para a impunidade evidente no país.

Palavras-chave: Reprodução Simulada. Psicologia Forense. Perícia Criminal.

\section{INTRODUÇÃO}

A Ciência Forense, de acordo com Garrido e Giovanelli (2009), e entendida como um conjunto de todo o conhecimento científico e técnico, que pode ser utilizado não só para esclarecer crimes, mas também para esclarecer diversas questões jurídicas (cíveis, criminais ou administrativas). É considerada um campo interdisciplinar porque envolve física, química, biologia, e outras diversas áreas do conhecimento. Seu objetivo principal é apoiar investigações relacionadas à justiça civil e criminal.

As ciências forenses possuem aplicações diversas em investigações criminais, como a Reprodução Simulada (RS). A RS, prevista no art. $7^{\circ}$ do Código de Processo Penal (CPP), Decreto-Lei № 3.689, de 3 de outubro de 194I (BRASIL, 194I), consiste em atividades periciais para verificar a possibilidade da existência de infrações penais de determinada forma; as autoridades policiais podem (exigir) a reprodução simulada de fatos, desde que isso não viole a moral ou a ordem pública (ZARZUELA, I991, p. 178).

'Perícia Criminal \& Ciências Forenses Instituto de Pós-Graduação - IPOG São Paulo, SP.E-mail: poulacantagessi@gmail.com. 
Esta prática é uma ferramenta que visa determinar a mecânica e o modus operandi do criminoso, além de esclarecer aspectos relevantes do crime, e identificar agravantes, como por exemplo a premeditação. Esta prática, segundo Portinho (2013), visa preencher as ocasionais lacunas encontradas na investigação.

Entre os diversos conhecimentos aplicados em RS está a psicologia. No Brasil, como em todo o mundo, ocorrem diferentes tipos de crimes diariamente, quando é utilizada a técnica de RS na reconstituição de um crime, devem ser analisados diversos fatores, entre eles os fatores psicológicos que influenciam nas ações das partes envolvidas. De acordo com um estudo realizado pelo Instituto de Pesquisas Econômicas Aplicadas, em parceria com o Ministério da Justiça, em uma investigação criminal, várias questões fundamentais surgem, em especial os fatores em potencial que podem impactar de forma positiva ou negativa a fidedignidade do testemunho e do reconhecimento. Assim, a psicologia é uma importante ferramenta para o melhor entendimento dos fatos analisados em uma RS.

Esta pesquisa tem o objetivo de evidenciar a importância da psicologia para a RS, apresentado conceitos relacionados a esta técnica, suas características técnicas e jurídicas, a relação entre a Psicologia e o Direito, informações acerca da psicologia forense e a psicologia forense nos processos de RS.

\section{METODOLOGIA}

O artigo é composto por uma revisão bibliográfica, desenvolvida através de consultas a revistas, artigos publicados e teses disponibilizadas na internet que tratam do tema. Com base em artigos publicados nos últimos 20 anos, com exceção para publicações do Dr. José Lopes Zarzuela, professor do Departamento de Medicina Forense da Faculdade de Direito da Universidade de São Paulo e Perito Criminal aposentado do Instituto de Criminalística de São Paulo, de grande relevância sobre o tema e para a elaboração do artigo. Para a pesquisa foram utilizadas as palavras chave: reprodução simulada, psicologia forense e perícia criminal.

A pesquisa será escrita de forma qualitativa, buscando a melhor compreensão da importância da psicologia nos processos de reprodução simulada. Esta pesquisa, com análise de dados survey, segundo Gil (2002, p. I4I) "o analista tem a sua frente somente os 
dados obtidos por meio do formulário, e sabe que não pode captar as experiências dos vários entrevistadores que o aplicaram”. Assim, de acordo com o autor, “convém, portanto, que o pesquisador desenvolva logo no início da pesquisa um quadro de referência teórico com vista em evitar especulações no momento de análise”.

No processo investigativo serão aplicados questionários para profissionais diversos, ligados à área criminal ou da psicologia, entre eles: policias, psicólogo, advogados, promotores e juízes, todos de forma anônima. Buscando avaliar questões acerca da importância da psicologia para a reprodução simulada, tema desse artigo, conforme as questões propostas no Anexo I.

\section{REFERENCIAL TEÓRICO}

\subsection{Conceitos}

A Reprodução Simulada (RS) é prevista no art. $7^{\circ}$ do CPP, a fim de "verificar a possibilidade de haver a infração (penal) sido praticada de determinado modo; a autoridade policial, poderá proceder (requisitar) à reprodução simulada dos fatos, desde que esta não contrarie a moralidade ou a ordem pública". Para entender a função dessa abordagem, é importante entender os conceitos de ordem e moralidade pública.

\section{I.I. Moralidade Pública}

Por moralidade, entende-se não só os bons costumes protegidos pela lei, mas também as normas de convivência ou de respeito próprio, que não estão previstas em lei, mas estão relacionadas à consciência das pessoas. Seu conceito é subjetivo e muda com o tempo e espaço, de uma cultura para outra, ou mesmo de uma época para a outra (ZARZUELA, I99I).

A moralidade exige decisões, ou seja, tomadas de atitude diante de casos concretos - exemplo clássico: dar esmola - o que requer raciocínio, percepção, memória, projeção de consequências, responsabilidade e até sacrifício. A reflexão sobre casos abstratos (imaginários), ou casos concretos já passados, não está no âmbito da moralidade, mas no estudo desta, a Ética ou Filosofia Moral. (LEMOS JUNIOR, 2020)

$\mathrm{Na}$ administração pública, a moralidade é um dos princípios constitucionais, previsto pela Constituição de 1988, no inciso LXXIII do artigo $5^{\circ}$. O princípio da moralidade exige da administração pública um comportamento não apenas lícito, mas também de acordo com a moral e os bons costumes, as regras da boa administração, os 
princípios de justiça e de equidade, bem como uma ideia comum de honestidade. Este princípio também é conhecido como o de probidade, que é a honestidade no modo de proceder (DI PIETRO, 20II). Zarzuela (I99I) afirma que, dentro da conjuntura processual penal, delitos contra a moralidade e os costumes, ainda são proibidos.

\subsubsection{Ordem Pública}

O conceito de Ordem Pública, de acordo com De Vincenzi e Machado (2009), é multifacetado e possui muitas definições. No entanto, mesmo nestes múltiplos conceitos, as regras de carácter público e as regras de transformação da proteção em direitos fundamentais devem sempre ser tidas em consideração nas decisões prudenciais sobre as penas condenadas fora do território nacional, mesmo na constituição de base.

A ordem pública, para Zarzuela (1991) é um conjunto de leis, política e ética. A violação dessas normas interrompe a coexistência harmoniosa da sociedade. Como no conceito de moralidade, existem padrões racionais que o empirismo carece de avaliação. Portanto, pode-se dizer que a ordem pública representa um conceito inerente a cada indivíduo.

\subsubsection{Reprodução Simulada}

O significado da palavra Reprodução na língua portuguesa é "Imitação fiel”, já Simulada é "fingido, imitado" ${ }^{2}$. Assim, pelo sentido literal destas palavras, entende-se que uma RS é imitar de forma fiel determinado ato. Dentro da prática pericial, a RS é uma perícia realizada pelo órgão oficial competente responsável, com a participação ativa das partes (vítimas, se sobreviventes e réus), testemunhas e informantes, e a participação ativa das partes, com o uso de fotos e esboços para ilustrar o caso. O objetivo é verificar a possibilidade científica de sua ocorrência ao descrevê-los (PORTINHO, 2017).

\subsection{Características da Reprodução Simulada}

A reconstituição de um delito, em muitos casos, tem grande valor decisivo no processo penal, permitindo que a decisão seja tomada com convicção pelos membros do

\footnotetext{
${ }^{2}$ Dicionário Online de Língua Portuguesa. Disponível em: < https://www.dicio.com.br/>. Acesso em 22 JAN 2021.
} 
Ministério Público ou do juiz de Direito. Sendo assim, este processo deve conter características que demonstrem ao juízo, de acordo com Zarzuela (1991):

I. Não é feito através do uso de coerção, ameaças ou abuso;

II. Não adulterou os depoimentos das partes e testemunhas, seja para encobrir um crime cometido por alguém no caso do réu;

III. A RS pode provar que é falsa a confissão de uma infração penal não cometida por pessoa ansiosa por divulgar.

Além das características iniciais supracitadas, a RS possui características Técnicas e Jurídicas que devem compor o inquérito, conforme exposto a seguir.

\subsection{Características Jurídicas}

$\mathrm{O}$ art. I6o do CPP determina que "os peritos elaborarão o laudo pericial, onde descreverão minuciosamente o que examinarem, e responderão aos quesitos formulados". A RS é um laudo pericial, com características jurídicas específicas, conforme descreve Zarzuela (199I):

I. A polícia ou as autoridades judiciais não podem legalmente obrigar o acusado a comparecer em tribunal para provar a sua reação ao crime;

II. Em alguns casos, a restituição pode constituir a condenação de um juiz, especialmente quando é acompanhada de uma confissão de culpa espontânea e confirmada e o réu é assistido por um membro do Ministério Público;

III. Defender casos que atentem contra a moral ou a ordem pública, de acordo com a legislação processual do RS;

IV. O juiz pode determinar pessoalmente a reconstituição do crime. Esta especificação se aplica às forças armadas e oficiais da Polida Militar no IPM;

V. O membro do Ministério Público tem o direito de requerer diretamente as medidas para efetuar a reorganização e (se o desejar) a atribuição legal que a acompanha.

Portinho (2013) destaca que a RS, enquadrada em uma perícia posterior a todos os demais exames de corpo de delito, orienta-se através das demais evidencias encontradas nos autos do inquérito policial. Deve-se comprara as versões apresentadas, relatar e discutir essas conclusões no relatório para comprovar a possibilidade de sua ocorrência. É importante notar que a RS tem natureza mista, opcional e complementar. 
Essa ferramenta mista utiliza todas as evidências do processo para chegar a uma conclusão, e é considerada opcional, devido ao fato de que só deve ser feita se for relevante para a investigação. $\mathrm{O}$ acusado não é obrigado a participar dos trabalhos, em respeito ao princípio da presunção de inocência (Nemo tenetur se detegere), podendo também ser utilizado como meio de defesa e de processo, sendo complementar porque visa suprir lacunas deixadas durante a investigação (PORTINHO, 2013).

\subsubsection{Características Técnicas}

Parte do procedimento operacional envolve a contratação de outras pessoas (geralmente peritos criminais e policiais) para desempenhar os papéis e funções que serão desempenhados no local quando o incidente ocorrer. Tem certa semelhança com a produção de um drama ou filme, onde os personagens são especialistas e integrantes da equipe de investigação, e o roteiro é montado a partir de depoimentos e evidências (MULLER, 2020).

A RS possui características técnicas específicas, Zarzuela descreve que o perito designado para orientar os trabalhos de reconstituição, do ponto de vista técnico deve (1991):

I. Estudar os autos do Inquérito Policial, Inquérito Policial Militar ou dos autos do Processo Criminal, e solicitar inspeções quando não forem enviadas com o pedido de inspeção;

II. Realizar audiências das partes - processar e reduzir vítimas e testemunhas à sua estabilidade;

III. Fixar o local de fato na fase de apuração do fato mais relevante no local dos fatos. Após confrontar os depoimentos das partes e testemunhas, acrescente legenda às fotos do registro de acordo com a sequência lógica dos fatos compreendidos pelas partes e testemunhas e conduzir análises apropriadas;

IV. Sempre que necessário e conveniente, certificar-se de preparar esboços ou desenhos e planos (em escala) quando necessário para a reconstrução;

V. Recomendar ao órgão requerente que conclua a reconstrução o mais rápido possível, pois à medida que o tempo passa do fato da reconstrução, muitas imagens são apagadas da memória, principalmente a memória de testemunhas, o que na verdade 
prejudica os interesses da justiça na investigação da ambiguidade das infrações penais.

\subsection{A Relação entre a Psicologia e o Direito}

Em casos de crimes com risco de vida, onde a polícia obtem poucas evidências físicas durante o processo de investigação, é necessário coletar evidências de testemunhais como prova. Em princípio, as testemunhas são ouvidas pela agência policial, no entanto, diferentes testemunhos sobre crimes podem significar diferentes versões dos mesmos fatos criminais, ou mesmo opostos. Portanto, essas versões precisam ser verificadas com mais cuidado para diferenciá-las umas das outras, a fim de obter versões mais próximas do que realmente aconteceu, e isto é feito por meio de profissionaus de psicologia (MACHADO, 2014).

A psicologia no âmbito jurídito possui tal importanciaque pode influenciar decisões judiciais, como dispoto no art. 26 do Código Penal (Brasil, 1940):

Art. 26. É isento de pena o agente que, por doença mental ou desenvolvimento mental incompleto ou retardado, era, ao tempo da ação ou da omissão, inteiramente incapaz de entender o caráter ilícito do fato ou de determinar-se de acordo com esse entendimento.

Parágrafo único. A pena pode ser reduzida de um a dois terços, se o agente, em virtude de perturbação de saúde mental ou por desenvolvimento mental incompleto ou retardado não era inteiramente capaz de entender o caráter ilícito do fato ou de determinar-se de acordo com esse entendimento.

Embora o direito e a psicologia sejam considerados campos diferentes, eles se complementam. A psicologia jurídica é um dos campos intimamente relacionados aos profissionais do direito. Portanto, a psicologia jurídica desempenha, em primeiro lugar, um papel em dois momentos: determinar o estado psicológico do acusado e determinar se é necessário acompanhamento psicossocial (aplicação de medidas de segurança) e, posteriormente, acompanhar a reabilitação psicológica e reeducação dos seus internos (OLIVEIRA, 20II).

\subsection{Psicologia Forense nos Processos de Reprodução Simulada}

Nas rotinas de trabalho tratando de reprodução simulada, relacionando-a com fatores psicológicos, quando estes relatos são feitos por adultos os problemas mais comuns enfrentados pelos especialistas, geralmente as descrições não são completamente falsas, é 
mais fácil para o suspeito mostrar o histórico real com os detalhes que são benéficos para ele. Com isso, verifica-se a importancia do profissional estar ciente de quais são os indícios de autenticidade, bem como buscar indícios de mentira no relato (RASSIN, I999).

Além disso, em uma reprodução simulada é importante analisar qualquer vestígio encontrado, inclusive os imateriais, que são os psicológicos e comportamentais. $\mathrm{Na}$ definição de Rosa (2015), um vestígio imaterial no ambito forense se trata de determinados tipos de comportamento associados à prática de ilicitos criminais. A Figura I apresenta a classificação dos vestígios.

Figura I - Classificação de vestígios

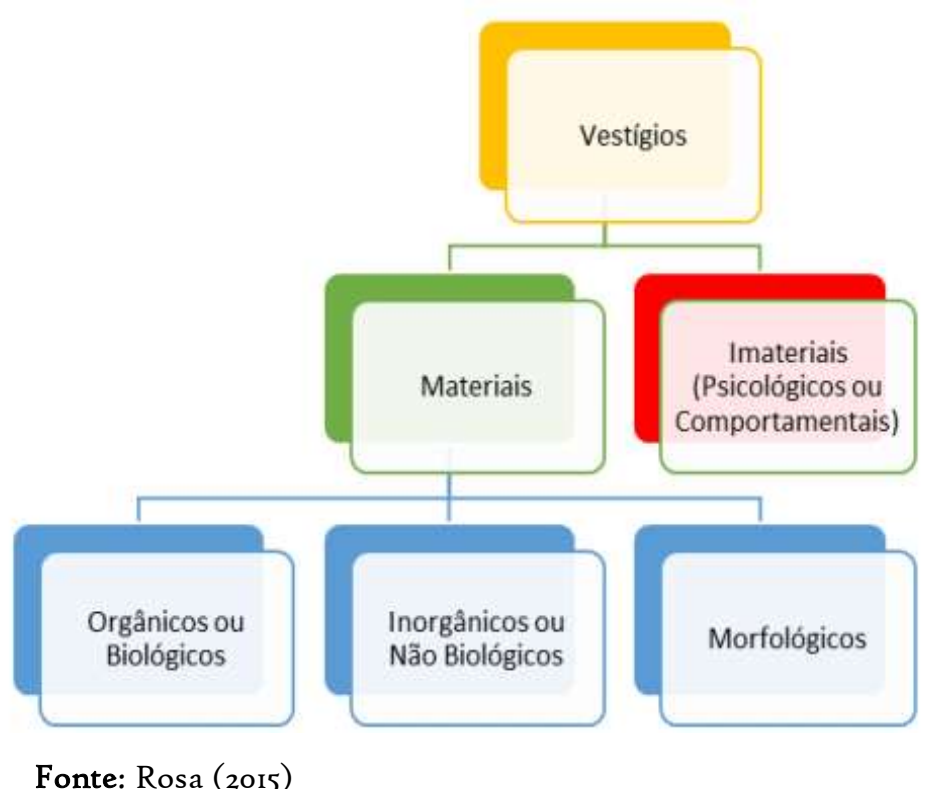

$\mathrm{Na}$ reprodução simulada, são consideradas diversas evidências comportamentais.

De acordo com Rosa (2015), as evidências comportamentais mais comuns são:

I. Extraído de depoimentos de vítimas, testemunhas ou suspeitos;

II. Informações obtidas em documentos coletados na cena do crime, como mapas, esboços, fotos, vídeos, entre outros;

III. Informações comportamentais de evidências físicas existentes e suas fotos e arquivos de vídeo;

IV. As feridas da vítima e seus documentos;

V. Informações relacionadas ao campo da vitimologia, ou seja, sua ocupação, atividades, biografia, idade, características físicas, entre outros. 
Em caso como os de crimes sexuais onde não há vestígios físicos, por exemplo, Portinho (2017) afirma que a reprodução simulada dos fatos é tida como um exame de corpo de delito indireto, apontando hipóteses do ocorrido em razão do decurso temporal, apontando o "caminho do crime", principalmente em casos onde a vítima não tem noção de seus atos, seja por ingenuidade advinda da tenra idade, ou por situações de capacidade cognitiva provisória dos atos.

Rosa (2015) afirma que a identificação, análise e interpretação de vestígios psicológicos ou comportamentais devem fazer parte dos procedimentos de rotina dos peritos criminais responsáveis pelas investigações da cena do crime para verificar e preparar relatórios. Este tipo de vestígio é muitas vezes ignorado pela tradição de formação da tradicional escola criminal e revela-se básico, quer seja utilizado como prova técnica, quer como ferramenta no processo de investigação.

\section{RESULTADOS DA PESQUISA}

A pesquisa foi realizada por meio da ferramenta Google Forms, por um período de seis meses no ano de 2021, com um total de 54 respondentes. Dentre os respondentes, a maior parte (22.2\%) são psicólogos, seguidos por Policias Militares (20.4\%) e Advogados (I4.8\%). As idades em sua maioria é entre 36 e 45 anos (37\%), seguido por entre 26 a 25 anos (31.5\%) e 46 a 55 anos (14.8\%). A Figura I apresenta um gráfico com os profissionais consultados.

Figura 2 - Profissão do respondente
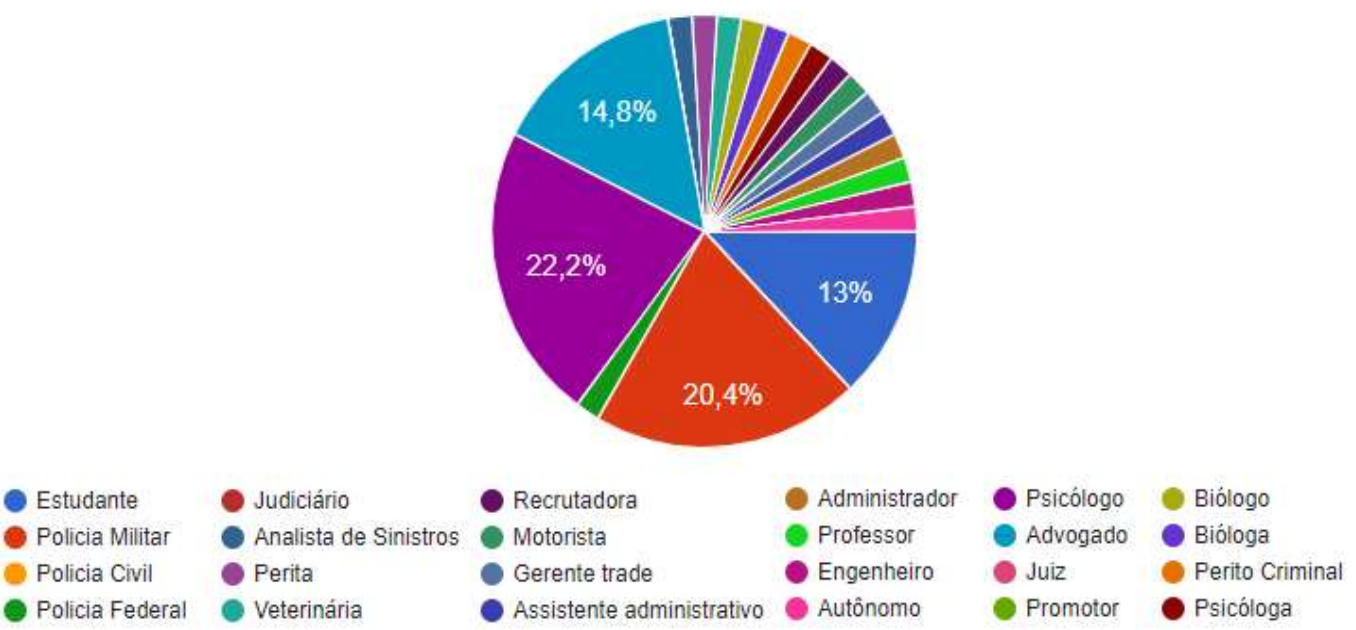

Fonte: Dados produzidos pelo o autor (2011) 
Quano ao tempo de profissão, estas variam. 29.6\% possuem menos de 5 anos na profissão, $27.8 \%$ possuem de Io a 17 anos de profissão, I8.5\% entre 18 a 25 anos de profissão, 16.7\% de 6 a 10 anos de profissão, 5.6\% de 26 a 35 anos de profissão e $1.9 \%$ mais de 46 anos de profissão. Entre esses profissionais, $42.6 \%$ indicaram conhecer a técnica de Reprodução Simulada, mas apenas $7.5 \%$ já trabalhou em algum caso que envolveu o uso desta técnica, porém, somente um profissional indicou a presença de profissional de psicologia durante o processo de RS. Quanto aos profissionais que indicaram ter trabalhado em casos com RS, indicaram como relevancia da RS para a resolução do caso:

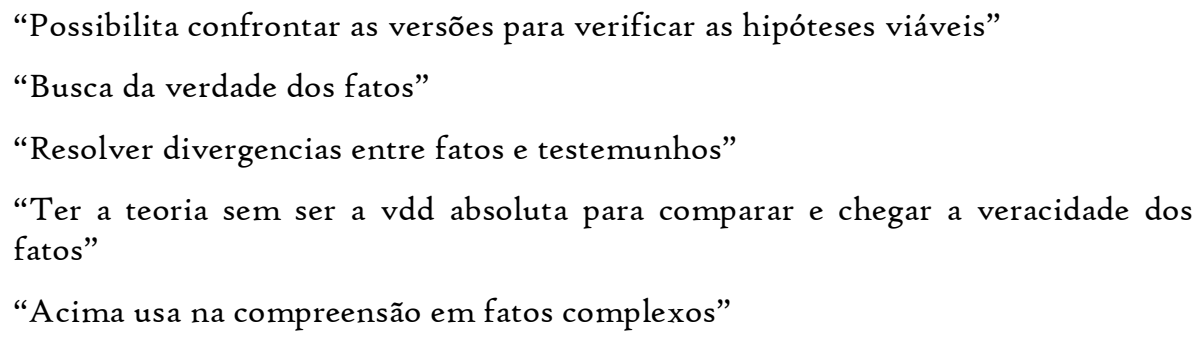

Quando questinados se consideram importante a presença de profissionais de perícia psicológica neste procedimento, $73.6 \%$ consideram importante a presença deste, justificando que:

"O profissional da psicologia auxiliará na resolução do caso"

“A Assistência psicológica coopera para manutenção das emoções dos envolvidos"

“Atuação técnico-científica na identificação da veracidade das informações prestadas na geração das versões (antes e durante a reprodução)”

"Muito importante para identificar a real situação de um crime ou para averiguar corretamente um suspeito"

"Para acompanhar as vítimas de forma correta em virtude da fragilidade do momento"

"Acredito que o profissional de psicologia seja o mais capacitado para acompanhar a simulação e não deixar que falhas possam ocorrer"

"O levantamento do perfil pode ajudar a identificar o sentido e os comportamentos adotados pelos envolvidos"

"A psicologia é importante na resolução de diversos casos por dar entendimento maior sobre as situações ocorridas e trabalhar soluções sem grandes conflitos"

"Acompanhamento da família no processo. E auxílio aos profissionais na compreensão da simulação”

“Toda técnica do estudo humano, associada aos indícios podem dar mais precisão na resolução de um caso ou/é direciona-lo a um caminho mais assertivo"

"Aumentar a confiabilidade dos dados" 
"Para que se verifique a condição psicológica do envolvido, prevenindo danos maiores ou distorções da realidade do fato"

“O profissional possui capacidade técnica em analisar a questão sob o aspecto das emoções. Conseguindo aproximar a percepção do depoente versus a análise reproduzida"

Com destaque para as seguintes respostas:

“O processo de investigação é multidisciplinar, sendo então necessários profissionais de diferentes áreas atuando na maior porte possível dos escopos da investigação. Isso não é diferente com o profissional da psicologia, que é muito importante em vários casos"

"Pessoas que passam por situações traumáticas precisam ser abordadas de uma maneira especial, por alguém que entenda o que ela está passando no momento, pois dependendo o tipo do crime, a pessoa muitas vezes tem um branco da situação ou até mesmo imagina coisas e detalhes que não aconteceram. Assim como se o agente agressor for participar, é importante para que se diagnostique comportamentos desviantes, psicopatologias ou passionalidade"

Verifica-se, os profissionais entrevistados consideram a relevancia da presencia de um profissional de psicologia no processo de Reprodução Simulada, em conformidade com os diversos aspectos teóricos da técnica. Pois, o comportamento humano possui diversas variais, e estas interefrem diretamente nos atos ilicitos, e devem ser devidamente analisados durante os processos de inquerito policial e outros procedimentos legais.

$\mathrm{Na}$ sequencia, foi questionado em quais tipos de crimes a presença de um perito em psicologia na reprodução simulada se faz mais importante, na opinião destes profissionais, com base em sua experiencia. Os dados são apresentados na Figura 3.

Figura 3 - Tipos de crimes a presença de um perito em psicologia na RS se faz mais importante

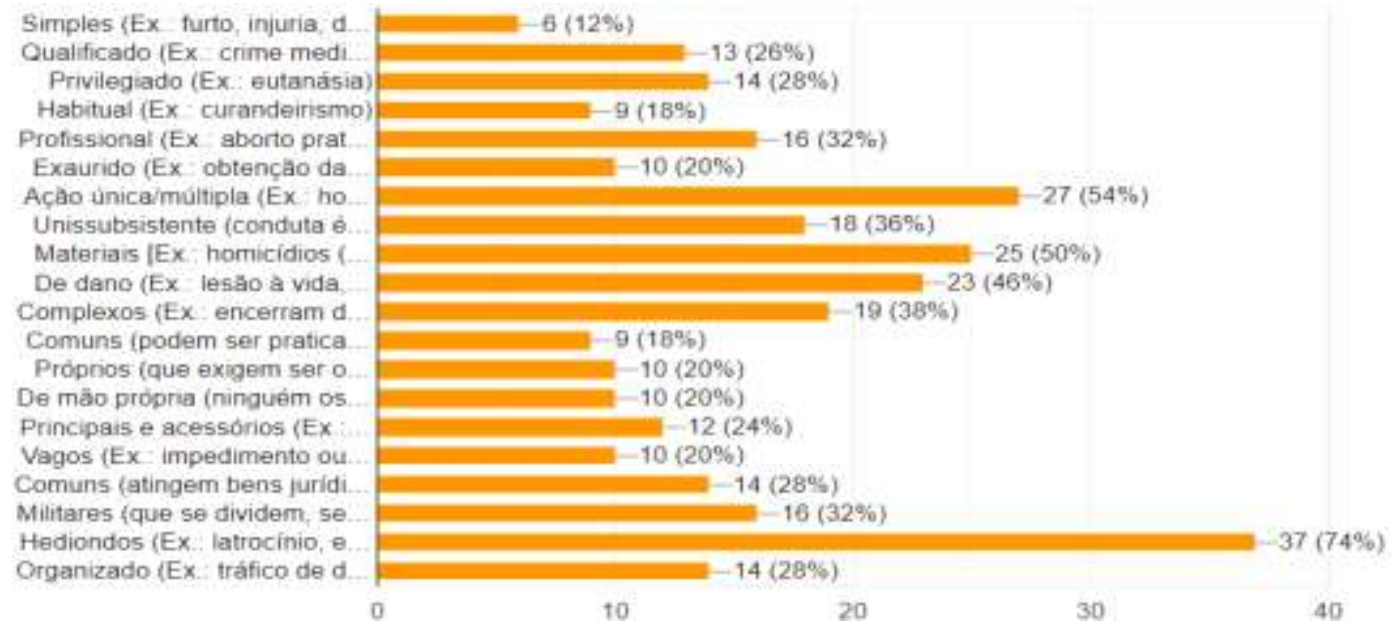

Fonte: Dados produzidos pelo o autor (2011) 
Os crimes que se destacaram entre os respondentes foram crimes hediondos (74\%), Exauridos (54\%), Materiais (50\%), de dano (46\%) e complexos (38\%). Os respondentes ainda opinaram sobre o uso da RS no esclarecimento de crimes que "a RS necessita de uma grupo pericial multidisciplinar e a psicologia apresenta métodos e técnicas úteis para a constatar a veracidade das informações fornecidas. Percepção de viés cognitivo que surja entre os demais peritos".

\section{CONSIDERAÇÕES FINAIS}

Esta pesquisa apresentou a importância da psicologia para Reprodução Simulada, buscando evidenciar a importância da psicologia para a RS, apresentado conceitos relacionados a esta técnica, suas características técnicas e jurídicas, a relação entre a Psicologia e o Direito, informações acerca da psicologia forense e a psicologia forense nos processos de RS.

A RS dentro da prática pericial é uma perícia realizada pelo órgão oficial competente responsável, com a participação ativa das partes (vítimas, se sobreviventes e réus), testemunhas e informantes, e a participação ativa das partes, com o uso de fotos e esboços para ilustrar o caso.

Neste contexto, a psicologia auxilia na determinação do estado psicológico do acusado e determinar se é necessário acompanhamento psicossocial, bem como analisar qualquer vestígio encontrado, inclusive os imateriais. A identificação, análise e interpretação de vestígios psicológicos ou comportamentais devem fazer parte dos procedimentos de rotina dos peritos criminais responsáveis pelas investigações da cena do crime para verificar e preparar relatórios.

Por meio dos dados obtidos, verificou-se que, mesmo a grande maioria dos respondentes considerando importante a presença de um profissional de psicologia nos processos de RS, eles são presentes na infima minoria dos casos.

O processo de RS envolve equipes multidisciplinares, mas há uma grande escasses de profissionais. No Brasil, de acordo com os dados do Instituto Sou da Paz (2020), a maioria das prisões são por crimes relacionados a drogas ou ao patrimônio, e I/3 destas sequer foi julgada. Io\% desta população carcerária está presa por crimes de homicídio, poré, 70\% dos crimes de homicídio no país seguem impunes. 
Os dados da pesquisa demonstararm que apenas $7.5 \%$ dos respondentes já trabalharam em casos de RS. Estes dados refletem a falta de resolução de homicícios no país. A falta de recursos das forças policiais e de investigação, bem como a precariedade dos inqueritos, entre outros fatores, contribuem para a impunidade evidente no país.

$\mathrm{Na}$ falta de provas materiais evidentes, recusos como o uso da psicologia em inqueritos policiais, são grandes recursos para a resolução de crimes, porém, diversos fatores fazem com que não haja a presença destes profissionais e se perpetue a impunidade no Brasil.

\section{REFERÊNCIAS}

DE VINCENZI, B. V.; MACHADO, C. R. A complexidade da Ordem Pública entre outras culturas. Revista Consultor Jurídico, in jun. 2009. Disponível em:

<https://www.conjur.com.br/2009-jun-II/conceito-ordem-publica-complexo-situacoesculturais-distintas>. Acesso em 22 JAN 2020.

DI PIETRO, M. S. Direito Administrativo. 24를 Ed, São Paulo: Atlas, 2011.

FREITAS, Marcel de Almeida. Psicologia Forense e Psicologia Jurídica: aproximações e distinções. De jure: revista jurídica do Ministério Público do Estado de Minas Gerais, Belo Horizonte, Vol.12. n.20, jan./jun.2013, p. 82-103.

GARRIDO, R. G.; GIOVANELLI, A. Criminalística: origens, evolução e descaminhos. Cadernos de Ciências Sociais Aplicadas, Ano, v. 4, 2009.

GIL, A.C. Como elaborar projetos de pesquisa. $4^{\underline{a}}$ ed. São Paulo: Atlas, 2002.

HUSS, M. T. Psicologia forense: pesquisa, prática clínica e aplicações. tradução: Sandra Maria Mallmann da Rosa ; revisão técnica: José Geraldo Vernet Taborda. Porto Alegre : Artmed, 20II.

INSTITUTO DE PESQUISA ECONÔMICA APLICADA - IPEA. Avanços científicos em Psicologia do Testemunho aplicados ao Reconhecimento Pessoal e aos Depoimentos Forenses. Ministério da Justiça, Secretaria de Assuntos Legislativos. Brasília: Ministério da Justiça, Secretaria de Assuntos Legislativos (SAL); Ipea, 2015.

LEMOS JUNIOR, I. O que é moralidade?. Ministério Público do Distrito Federal e Territórios, 2020. Disponível em: https://www.mpdft.mp.br/portal/index.php/comunicacao-menu/artigos-menu/artigoslista/537-o-que-e-moralidade>. Acesso em 22 JAN 2020.

MACHADO, Patrícia Vasconcelos. Estudo exploratório sobre critérios de veracidade em relatos de eventos de vida: considerações para a perícia psicológica criminal de adultos. 


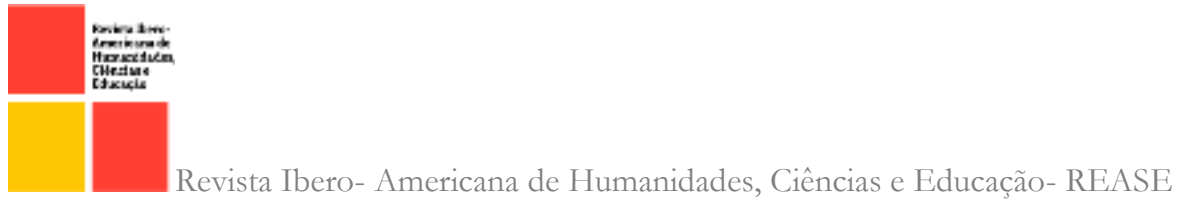

2014. Dissertação (Mestrado em Psicologia) - Universidade Federal do Rio Grande do Sul. Porto Alegre, 2014.

MOURA, S. F. Livro didático de Psicologia aplicada ao Direito. Rio de Janeiro: Editora Universidade Estácio de Sá, 2014

MULLER, Cleber. Reprodução simulada dos fatos: as múltiplas atuações da perícia criminal na busca da verdade dos fatos. Revista Jus Navigandi, ISSN 1518-4862, Teresina, ano 25, n. 6070, 13 fev. 2020.

PEREIRA, Adriana Farias Braum. Reprodução simulada dos fatos: carência de regulamentação pelo CPP sob o ponto de vista da perícia criminal. In: Âmbito Jurídico, Rio Grande, XX, n. I6o, maio 2017. Disponível em: <http://www.ambitojuridico.com.br/site/?n_link=revista_artigos_leitura\&artigo_id $=\mathrm{I} 89 \mathrm{II} \&$ revista_caderno $=22>$. Acesso em ro mar 2019.

PORTINHO, Andrei Röehrs. A prova pericial nos delitos sexuais e a (im) possibilidade de tentativa de estupro: um estudo de caso em perícias criminais de reprodução simulada realizadas no rio grande do sul entre os anos de 2013 e 2014. Justiça \& Sociedade-Revista do Curso de Direito do IPA, v. 2, n. I, p. 241-250, 2017.

PORTINHO, Andrei Röehrs. Reprodução simulada dos fatos: aspectos acerca do art. $7^{\circ}$ do Código de Processo Penal. In: Âmbito Jurídico, Rio Grande, XVI, n. II5, ago 2013. Disponível em: 〈http://www.ambitojuridico.com.br/site/?n_link=revista_artigos_leitura\&artigo_id=13515>. Acesso em io mar 2019.

OLIVEIRA, H. A psicologia jurídica e a psicanálise freudiana como bases teórico-práticas para uma abordagem interdisciplinar do Direito. Revista dos Estudantes de Direito da UnB, 2011, I0: 2-17.

RODRIGUES, M.J.R. Perfis Criminais: Validade de Uma Técnica Forense. 2010. Tese (Mestrado em Medicina Legal) - Instituto de Ciências Biomédicas de Abel Salazar da Universidade do Porto. Porto, 2010.

RODRIGUES, Cláudio Vilela; SILVA, Márcia Terra da; TRUZZI, Oswaldo Mário Serra. Perícia criminal: uma abordagem de serviços. Gestão e Produção, v. 17, n. 4, p. 843857, 2010.

ROSA, Cássio Thyone Almeida. Vestígios psicológicos ou comportamentais na cena de crime: uma evidência subutilizada no arcabouço pericial brasileiro. Revista Brasileira de Criminalística, v. 4, n. 3, p. 15-27, 2015.

ROVINSKI, S. L. R. Fundamentos da perícia psicológica forense. 23 ed. São Paulo: Vetor, 2007 
TAVARES, Kaylla Maria Castro. Avaliação psicológica no contexto jurídico: demandas e práticas no direito de família. Revista Especialize On-line IPOG, Goiânia - Ano 9, Edição no 15 Vol. or julho/2018.

TRIBUNAL DE JUSTIÇA DO ESTADO DE SÃO PAULO - TJSP. Atuação dos profissionais de serviço social e psicologia: manual de procedimentos técnicos - Infância e Juventude. São Paulo: TJSP, 2017. Disponível em: < https://www.tjsp.jus.br/Download/Corregedoria/pdf/manual_de_procedimentos.pdf〉.

Acesso em 12 mar 2019.

ZARZUELA, José Lopes. Reconstituição: aspectos técnicos e jurídicos. Revista da Faculdade de Direito, Universidade de São Paulo, v. 86, p. I77-ı89, 1991.

ZARZUELA, J. L. A importância da fotografia judiciária na perícia. Revista Da Faculdade De Direito, Universidade De São Paulo, v. 87, p. 253-261, 1992.

INSTITUTO SOU DA PAZ. Qual a taxa de esclarecimento de assassinatos no Brasil. 2020. Disponível em: <https://soudapaz.org/noticias/nexo-qual-a-taxa-de-esclarecimentode-assassinatos-no-brasil/>. Acesso em 30 OUT 2021. 